\title{
A 12-day-old male newborn with extensive vesicles and fever
}

\author{
Kritsana Kongthavonsakul, ${ }^{1}$ Charles Henry Washington, ${ }^{2}$ Chulabhorn Pruksachatkun, ${ }^{1}$ \\ Peninnah Oberdorfer ${ }^{1}$
}

1Pediatric Department, Faculty of Medicine, Chiang Mai, Thailand;

2Emergency Medicine Department, University of New Mexico Hospital, Albuquerque, United States

Correspondence to Dr Peninnah Oberdorfer, aoberdor@med.cmu.ac.th

\section{Summary}

Neonatal varicella infection is a rare condition since vaccine introduction. The authors report the case of a 12-day-old male who presented with a fever and generalised vesicular eruption. The patient's mother had varicella infection 1 day before delivery without treatment. The neonate initially did not receive prophylaxis or treatment. He subsequently was started on intravenous acyclovir and recovered without further complications or sequelae. Prompt diagnosis and treatment for maternal prenatal varicella infection is necessary to prevent infection in the newborn, and healthcare provider awareness to avoid nosocomial transmission.

\section{BACKGROUND}

Neonatal varicella infection is a rare condition with an incidence of 2-6 per 100000 live births per year. ${ }^{12}$ Neonates born 2 days before or 4 days after the onset of maternal varicella can develop serious illness. Without treatment, the case death rate approaches $30 \%{ }^{3}$ The American Association of Paediatrics recommends administration of varicella zoster immunoglobulin (VZIG) to newborns who

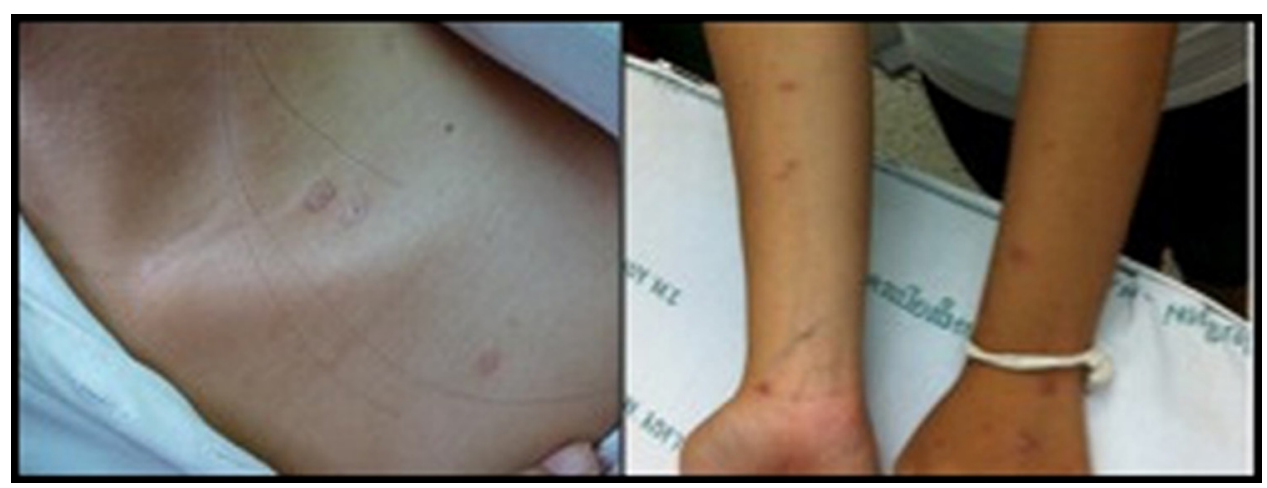

Figure 1 Multiple brownish macules on mother's left upper anterior chest and bilateral forearms on admission to CMUH.

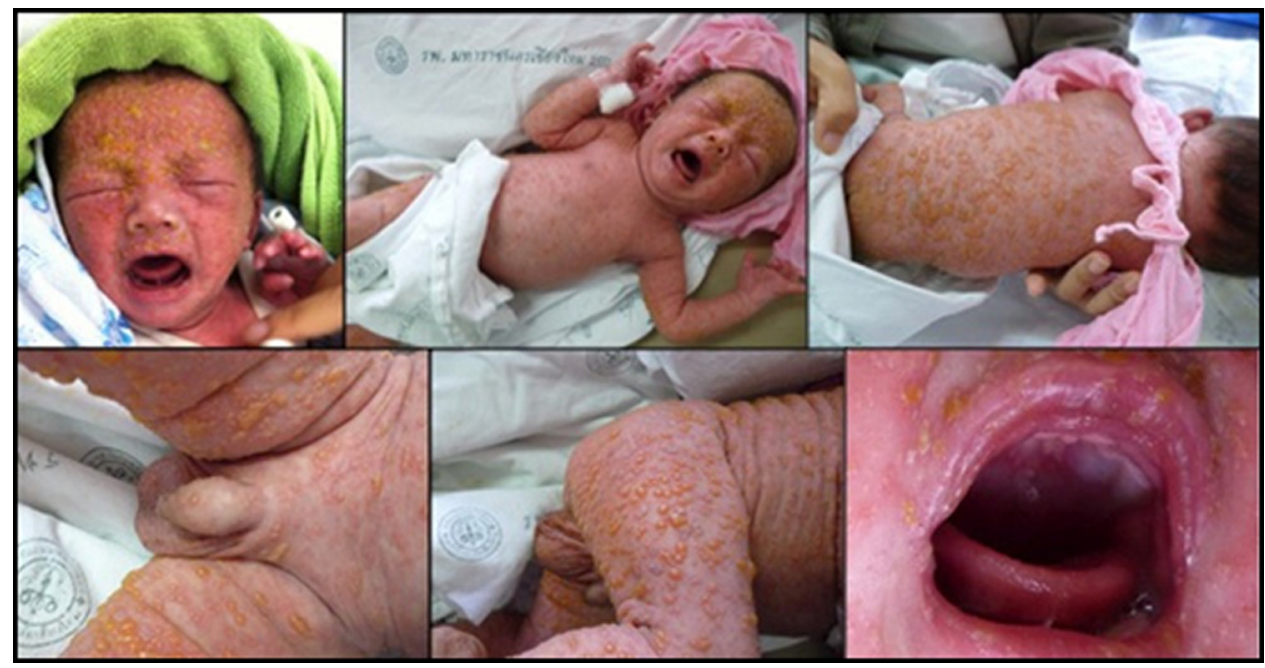

Figure 2 Generalised vesicles on day 3 of disease. 


\section{BMJ Case Reports}

are born from mothers with a varicella infection 5 days before delivery and 2 days after delivery. ${ }^{4}$

We are presented an opportunity for healthcare provider education on the identification of varicella infections in adults and infants.

\section{CASE PRESENTATION}

A 17-year-old female, an indigenous minority (Shan) from Burma who has been living in Thailand for 15 years, G2P1001, with eight prenatal visits, and no problems

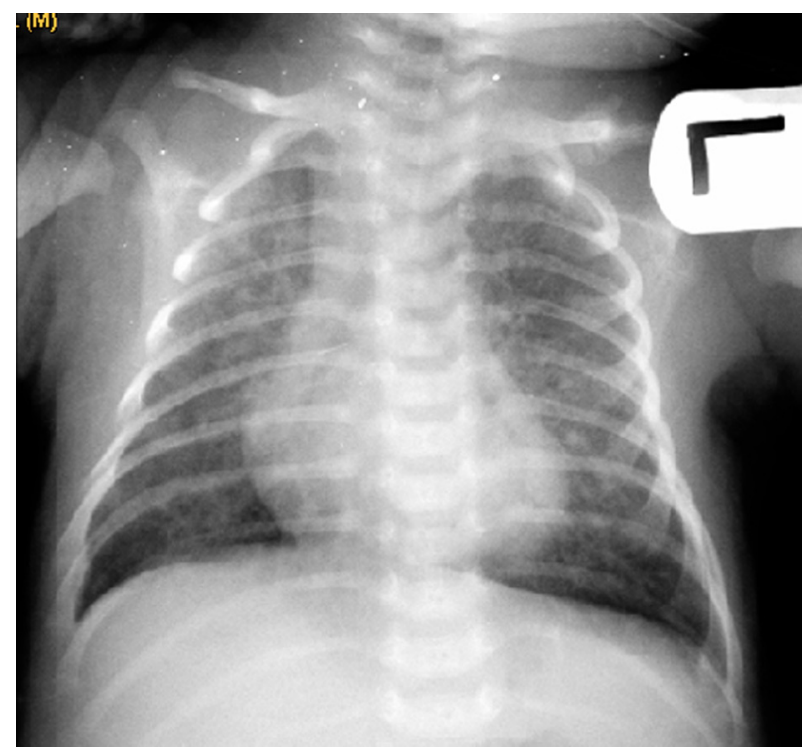

Figure 3 Chest radiograph on admission to CMUH with perihilar infiltrates at both lungs. during her previous pregnancy gave birth at 40 weeks by normal spontaneous vaginal delivery. She developed scattered vesicles on her trunk 1 day prior to delivery (figure 1). The rash subsequently extended to her face and extremities. She denied associated symptoms including fever, myalgias, cough, dyspnoea and urethalgia. She did not receive any treatment. After delivery the mother was separated from the baby for 2 days. She gave a history of a concurrent varicella infection of her nephew who stayed in the same house as her 3 days before she gave birth. Initial assessment on birth included Apgar scores of 10 and 10 ( 1 and 5 min respectively), birth weight of 2980 grams, length of $53 \mathrm{~cm}$ and head circumference of $33 \mathrm{~cm}$.

Nine days after birth, the neonate was taken to a rural clinic in northern Thailand with a rash and fever for 3 days. He was prescribed amoxicillin syrup, but subsequently deteriorated. Three days later, he presented to the Chiang Mai University Hospital (CMUH) with an erythematous vesicular rash, which began on his face and subsequently extended to the trunk and extremities. Per the mother the neonate was irritable with a tactile fever, but did not have rhinorrhea, cough or diarrhoea. He was breastfed with normal oral intake and urine output.

On presentation to $\mathrm{CMUH}$, the physical examination was remarkable for a temperature of $39^{\circ} \mathrm{C}$, irritability, cluster of small shallow ulcers on erythematous base on the hard palate and generalised tense vesicles, with some areas of yellowish crusts, including the face, lips, genitalia, palms and soles (figure 2).

\section{INVESTIGATIONS}

Laboratory examinations were remarkable for haemoglobin (12.8\%), haematocrit (37.5\%) and total white blood

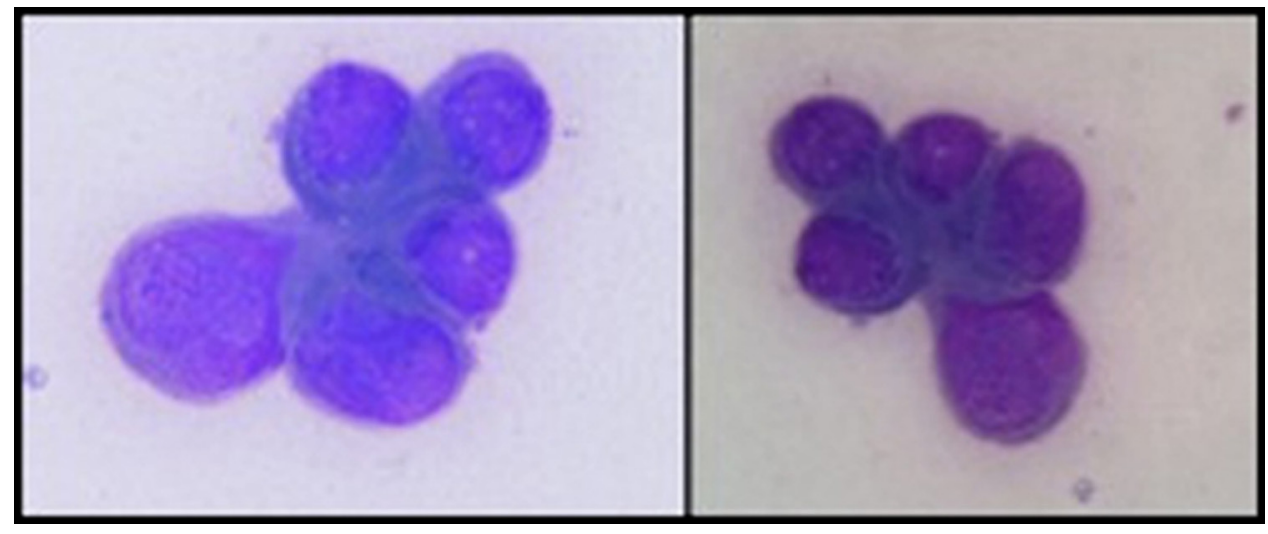

Figure 4 Tzanck smear taken from intact vesicle on trunk showing multinucleated giant cells.

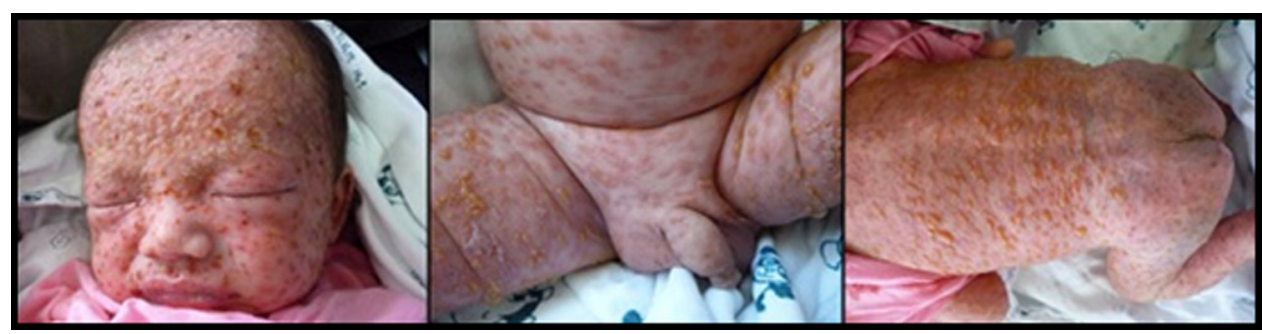

Figure 5 Pictures of rash $24 \mathrm{~h}$ after initiation of treatment. 


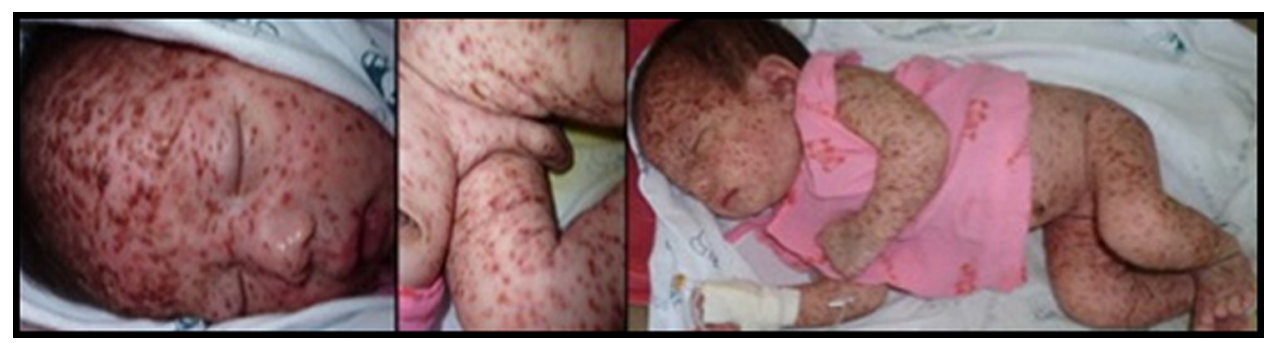

Figure 6 Pictures of rash $96 \mathrm{~h}$ after initiation of treatment.

cell counts (8116 cells/ccmm, ${ }^{3}$ lymphocytes (48\%)). Chest radiograph showed perihilar infiltrates (figure 3 ). Tzanck smear showed multi-nucleated giant cell (figure 4). Gram stain of lesion revealed numerous white blood cells with a predominance of neutrophils and gram positive cocci. Culture from skin lesion showed Staphylococcus aureus. Blood cultures were negative.

\section{DIFFERENTIAL DIAGNOSIS}

Neonatal varicella infection with secondary superimposed bacterial infection of the skin and pneumonia.

\section{TREATMENT}

The neonate was started on intravenous acyclovir $(60 \mathrm{mg} /$ $\mathrm{kg} /$ day) along with supportive therapies. Additionally, intravenous ampicillin and cefotaxime were also started empirically pending culture results.

\section{OUTCOME AND FOLLOW-UP}

The boy has completely recovered after treatment and was discharged home on day 14 with progressive resolution of rash (figures 5 and 6).

\section{DISCUSSION}

The first case report/review of neonatal varicella that we identified was from 1967, which reported a total of 34 cases from 1878 to $1965 .^{5}$ A case series from 1988 to 1995 in Bangkok reported 26 cases of neonatal varicella, 12 infected perinatally and 14 postnatally, with the most common complications including pyoderma (35\%), sepsis $(30 \%)$ and pneumonia (26\%). ${ }^{6}$ To our knowledge, this is the first case reported in Thailand outside of Bangkok.

Generally the diagnosis of varicella depends on a history of close exposure to an index case, and the characteristic vesicular rash and fever. ${ }^{3} 4$ This case brings up some interesting points. Often it is difficult to identify the source of infection. The mother's exposure to her nephew with a possible varicella infection may have led her to contract the infection before delivery, but per report there was not a sufficient incubation period to explain transmission. We suspected that both the mother and her nephew might have been exposed to another unidentified index case during a similar period. Multiple provider-patient interactions occurred without recognition of the infection in the mother before and after delivery, and the neonate. This led to missed treatment with acyclovir for the mother, neonatal VZIG prophylaxis and early initiation of acyclovir treatment for the neonate. Additionally, because of this delay contact tracing did not occur. Once the varicella infection was identified, the neonate was treated promptly, isolated from others, and fortunately has not had identifiable sequelae. Subsequently, no new cases were identified.

\section{Learning points}

- Recognition of skin lesions, prompt diagnosis, treatment of pregnant women with varicella and neonatal prophylaxis are necessary to prevent neonatal varicella.

- Initial maternal treatment includes oral acyclovir within $24 \mathrm{~h}$ of onset of rash to decrease maternal symptoms and complications. ${ }^{4}$ If the maternal varicella rash develops 5 days before delivery or 2 days after delivery, VZIG should be administered for postexposure prophylaxis. ${ }^{4}$ Intravenous acyclovir may be used for prophylaxis if VZIG is not available or more than $96 \mathrm{~h}$ have passed since exposure. ${ }^{4}$

- Neonates with suspected perinatal varicella exposure should receive VZIG.

- Neonatal varicella treatment includes intravenous acyclovir and supportive/symptomatic care is indicated, along with additional antibiotics if superimposed bacterial infection is suspected.

- A contact investigation should be conducted among all household members to identify immunocompromised individuals and need for post exposure prophylaxis.

Acknowledgements The authors would like to thank Dr Kalada Wongworapat who helped with data collection, and Albert $L$ Oberdorfer who edited the final draft.

Competing interests None.

Patient consent Obtained.

\section{REFERENCES}

1. Forrest J, Mego S, Burgess M. Congenital and neonatal varicella in Australia. $J$ Paediatr Child Health 2000;36:108-13.

2. Khandaker G, Marshall $H$, Peadon E, et al. Congenital and neonatal varicella: impact of the national varicella vaccination programme in Australia. Arch Dis Child 2011;96:453-6.

3. Arvin AM. Varicella-zoster virus. In: Long S, Pickering L, Prober C, eds. Principles and Practice of Pediatric Infectious Disease. Second Edition. Philadelphia, PA: Churchill-Livingstone 2003:1041-9.

4. American Academy of Pediatrics. Varicella-Zoster Infections. In: Pickering LK, Baker CJ, Kimberlin DW, Long SS, eds. Red Book: 2009 Report of the Committee on Infectious Diseases. 28th Edition. Elk Grove Village, Illinois: American Academy of Pediatrics 2009:714-27.

5. Hyatt HW. Neonatal varicella. Report of a case in a five-day-old infant and review of the literature. J Natl Med Assoc 1967;59:32-4.

6. Singalavanija S, Limpongsanurak W, Horpoapan $S$, et al. Neonatal varicella: a report of 26 cases. J Med Assoc Thai 1999;82:957-62. 


\section{BMJ Case Reports}

This pdf has been created automatically from the final edited text and images.

Copyright 2012 BMJ Publishing Group. All rights reserved. For permission to reuse any of this content visit http://group.bmj.com/group/rights-licensing/permissions.

BMJ Case Report Fellows may re-use this article for personal use and teaching without any further permission.

Please cite this article as follows (you will need to access the article online to obtain the date of publication).

Kongthavonsakul K, Washington CH, Pruksachatkun C, Oberdorfer P. A 12-day-old male newborn with extensive vesicles and fever. BMJ Case Reports 2012;10.1136/bcr.11.2011.5211, Published XXX

Become a Fellow of BMJ Case Reports today and you can:

- Submit as many cases as you like

- Enjoy fast sympathetic peer review and rapid publication of accepted articles

- Access all the published articles

- Re-use any of the published material for personal use and teaching without further permission

For information on Institutional Fellowships contact consortiasales@bmjgroup.com

Visit casereports.bmj.com for more articles like this and to become a Fellow 